\title{
Every step counts: towards a smoke free society
}

Although with some ups and downs, the control of the tobacco epidemic has made some progress over the past years across different countries in Europe. ${ }^{1-3}$ Of course, it is hard to attribute decreased tobacco consumption to a single action, but this process has been parallel to a set of policies resulting in the control of tobacco promotion, more public education, higher taxes (leading to higher cost of cigarettes), lower availability of tobacco products for teens, and the expansion of smoke free areas. ${ }^{4}$

In different societies, tobacco plays different roles. This depends both on specific features of each culture, and on the stage of the tobacco epidemic in it. ${ }^{5}$ Even within different subgroups in a given society, tobacco is entrenched differently. This is why René Dubos' principle of “acting locally and thinking globally" applies so well to tobacco control. The progress towards a smoke free society is built over a tremendous amount of individual and community efforts, as any societal change of wide dimensions. Some are successful, some fail. A few are well known initiatives that caught the public interest or were reported in professional journals, but most go unnoticed except for the direct actors. Major policies aimed at smoking control will facilitate local initiatives; however, without commitment and effort by people at the grassroots level, success cannot be taken for granted. Most local initiatives are small in size and involve a handful of people in a medical office, a classroom, or a workplace; they are unlikely to be reported in the media. Yet, very often, the potential is great for learning from other peoples experiences and applying it to another setting. It is well known that to import a public health programme to a different context leads often to failure. However, understanding the experiences of others, and applying their principles or approaches to our work may provide new insights that may result in improved action, which may yield new success. ${ }^{6}$ Thus, reporting good descriptions of projects and fair evaluations is important in public health, specifically in health promotion, for tobacco control and also for other issues.

In this issue of the journal, Etter, Ronchi and Perneger ${ }^{7}$ report an effort to expand smoke free areas in a university setting in Switzerland, a developed country without a long record of smoking control efforts, and with a very visible presence of the tobacco industry in its economy. The project may be of value to professionals in other settings, and thus its publication in the journal is of interest. It deals with smoking control in a difficult setting: a university context is dominated by students, most belonging to an age group where the harmful effects of tobacco are not yet evident. With a comparatively short smoking history and good personal health, young smokers are less likely to consider quitting seriously and to succeed. ${ }^{8}$ A substantial proportion of them are also more likely to perceive smoking control efforts as a personal aggression. In such a context, the academic and non-academic staff also play a crucial part. It is often the case that the less skilled staff among nonacademic personnel, develop sensitive positions towards some issues pressed by students and the academic staff, which may be perceived as class aggressions. Smoking prevalence shows clear social class gradients in Switzerland and other European countries, at least among men. ${ }^{9}$

Pushing smoke free areas is a viable health promotion strategy. ${ }^{10} 11$ It does convey to all the community the message that smoking is not the social norm; it does protect non-smokers from environmental tobacco smoke; and it does provide a more favourable context for dissonant smokers to quit (although there may be only a few in this setting). In the long term, it is likely that it helps many smokers move along their process of change. ${ }^{12}$ Besides, when school tobacco education programmes postpone the start of smoking, it is important to have tobacco policies that will maintain non-smoking through the young adult years. ${ }^{13}$

The evaluation design does have some limitations, as the principles of experimental design cannot always be kept in actual interventions. ${ }^{14}$ In this case, participation and follow up show some shortcomings. Besides, basing the evaluation in perceived environmental tobacco smoke as reported in a questionnaire has limited validity: not only because of differential perceptions by smokers and non-smokers, but also by a seasonal effect. However, the evidence presented confirms the feasibility of expanding smoke free areas in academic settings, without negative side effects and with a wide consensus, when smoking control efforts were previously scarce. An environment more favourable for smoking cessation and freeing all from passive smoke was obtained. There are gains from such a project, although no actual increase in smoking cessation was observed.

Some lessons may be learned from this experience. Firstly, (but often forgotten), not everything works in health promotion: no reduction in smoking was achieved. It may come as no surprise given the age pattern and motivations of people who quit smoking. However, other researchers have provided evidence of an interest for smoking cessation among young students, and of viable programmes to help them quit. ${ }^{15}$ Other smoking segments of the target group, with a higher age and a longer smoking history may be ready for cessation interventions. Secondly, demand and need do not always match. No demand for cessation services emerged. This may question their format, their accessibility, and whether they were suited for the target population. Finally, we must not forget that appropriate marketing channels are crucial for successful health promotion programmes.

JOAN R VILLALBí

Institut Municipal de Salut Pública, Barcelona, Pl Lesseps 1, 08023 Barcelona, Spain

1 Hill C. Trends in tobacco smoking and consequences on health in France. Prev Med 1998;27:514-19.

2 Pagano R, La Vechia C, Decarli A. Smoking in Italy, 1995. Tumori 1998;84: 456-9.

3 Pardell H, Saltó E, Tresserras R, et al. Smoking prevalence trends in Catalonia, Spain, 1982-1994. Med Clin (Barc) 1997;109:125-9.

4 Chapman S. Unraveling gossamer with boxing gloves: problems in explaining the decline in smoking. $B M \mathcal{F} 1993 ; 307: 429-32$.

Lopez AD, Collishaw NE, Piha T. A descriptive model of the cigarette epidemic in developed countries. Tobacco Control 1994;3:242-7.

6 Hawe P, Degeling D, Hall J. Evaluating health promotion: a health worker's guide. Sydney: Mac Lennan and Petty Pty Ltd, 1990.

7 Etter JF, Ronchi A, Perneger TV. Short-term impact of a university based smoke free campaign. $\mathcal{F}$ Epidemiol Community Health 1999;53:710-15.

8 Lamkin L, Davis B, Kamen A. Rationale for smoking cessation interventions for youth. Prev Med 1998;27:

9 Curtin F, Morabia A, Bernstein M. Smoking behavior in a Swiss urban population: the role of gender and education. Prev Med 1997;26:658-63.

10 Pierce JP, Naquin M, Gilpin E, et al. Smoking initiation in the United Ptates: a role for worksite and college smoking bans. $₹$ Natl Cancer Inst 1991;83:1009-13.

11 Villalbí JR, Ballestín M. Developing smoking control policies. Health Promotion International 1994; 9:99-104.

12 Prochaska JO, Di Clemente CC, Norcross JC. Stages and processes of selfchange in smoking: towards an integrative model of change. 7 Consult Clin Psychol 1993;51:390-3.

13 Wechsler H, Rigotti NA, Glehill-Hoyt J, et al. Increased levels of cigarette use among college students: a cause for national concern. $¥ A M A$ 1998;280: 1673-8.

14 Windsor RA, Baranowski T, Clark N, et al. Evaluation of health promotion and health education programs. Palo Alto, CA: Mayfield Publishing, 1984.

15 Emmons KM, Wechsler H, Dowdall G, et al. Predictors of smoking among US college students. Am F Public Health 1998;88:104-7. 